\title{
Debating the use of social media in higher education in Australasia: Where are we now?
}

\author{
Julie Willems \\ Monash University, Australia \\ Chie Adachi, Francesca Bussey, Iain Doherty \\ Deakin University, Australia \\ Henk Huijser \\ Queensland University of Technology, Australia
}

The integration of social media into higher education is having a significant impact on learning and teaching. As they become enmeshed in the fabric of academia, they are also becoming a site of contestation, especially in relation to teaching and learning. This research paper explores the key issues dominating current debates about the use of social media in higher education in Australasia. By exploring themes emerging from a debate around the use of social media in higher education in Australasia, it integrates additional comments from the collective wisdom of experienced colleagues from around the globe, as captured in the debate's Twitter feed and live Periscope streaming. These comments highlight points of sensitivity in the adoption of social media in higher education in Australasia. This paper presents the findings and some key ideas that emerged from the debate.

\section{Introduction}

Social media are an important feature of contemporary communication, encompassing a large array of Internet-based tools and platforms that increase and enhance the sharing of information. Dabbagh and Kitsantas (2011, p. 1) broadly define social media as "a variety of networked tools or technologies that emphasise the social aspects of the Internet as a channel for communication, collaboration, and creative expression”. This new form of media makes the transfer of text, photos, audio, video, and information in general increasingly fluid among internet users.

While the term social media is often used synonymously with social networks such as Facebook and Twitter, it is an umbrella term that encompasses 13 different subtypes, including blogging tools, business and social networking tools, forums, photo sharing tools, business collaboration tools, service and product reviews, research networks, video sharing tools, and virtual worlds (Aichner \& Jacob, 2015). Key characteristics of all the social media, to some extent, include the ability to produce, as well as consume, content in a networked environment. Bruns (2010) has labelled this ability to simultaneously produce and use as "produsage”. The affordances of social media are potentially attractive in educational contexts, especially when considering active and social learning approaches (Macfarlane, 2015; Zheng, Niiya, \& Warschauer, 2015).

Arguments about the benefits and utility of digital technology in universities present a familiar motif (Facer, 2011; Selwyn, 2016), and the potential for the use of social media in higher education (HE) in Australasia, as explored in this paper, treads some old ground in this respect. Any reasonable history of digital technology and universities will argue that this is a contested space, characterised by expressions ranging from overweening enthusiasms, through to overt anxieties about the contamination of the institution (Selwyn, 2016). As a result, there remain low levels of commitment to social media in most Australasian educational institutions with relevant policies at various stages of development (Willems, Adachi, \& Grevtseva, 2016). Despite this, social media appear to have permeated the institution, albeit in a fairly ad hoc manner, with frequently positive results (Junco, Heiberger, \& Loken, 2011). Interestingly then, whilst commentators a decade ago voiced concerns that social media might lower standards, trivialise the institution and breed a generation of "intellectual kleptomaniacs" (Keen, 2007), social media have, in a sense, snuck in the back door. 
Indeed in the intervening 10 years, the use of social media has rapidly permeated the HE sector globally (Johnson et al., 2016; Kaplan \& Haenlein, 2010) and there is evidence that institutional approaches aside, students are making use of social media in their learning (Smith, 2017). However, the more they proliferate, the more debate arises about the pros and cons of their adoption. While many would argue that it is no longer really a matter of whether to adopt social media in HE, but rather how best to do so, this situation still leads many institutions to adopt a cautious position, thus creating a need to explore the risks and the opportunities presented by social media for teaching and learning (Au, Lam, \& Chan, 2015; Universities and Colleges Information Systems Association [UCISA], 2015).

\section{Research problem and theoretical framework}

In order to maintain a manageable focus for this research, the primary area of focus was the utility of social media for enhancing student learning, because social media must potentially add value to teaching and learning if we are to move onto questions of, for example, institutional adoption of social media in teaching and learning or development of staff capability in this area. If one function of social media is that they act as a channel for communication, collaboration, and creative expression (Dabbagh \& Kitsantas, 2011), then the question becomes how to effectively use these channels to enhance teaching and learning.

The Community of Inquiry model has a long history (Anderson, 2017) and suggests that learning occurs through the interaction of three core components: cognitive presence, teaching presence, and social presence (Rourke, Anderson, Garrison, \& Archer, 1999). Thus, it would be tempting to conclude that the utility of social media lies first and foremost in facilitating social presence, defined as the ability of learners to project themselves socially and emotionally in a community of inquiry (Rourke et al., 1999). However, social media can potentially also facilitate cognitive presence whereby students construct meaning through sustained communication and teacher presence that includes facilitating active learning (Rourke et al., 1999).

A second model with a long history (Anderson, 2017), which addresses the potential utility of social media for enhancing teaching and learning, relates to social presence (Miyazoe \& Anderson, 2013) and can be referred to as the three types of interaction model. This model has been expanded in recent times to embrace the potential of networks and informal learning opportunities as interaction types (Croxton, 2014; Miyazoe \& Anderson, 2015). Looking at the model in its original form we can conceive of the educational context in terms of three interaction types: the interaction between learner and content, the interaction between learner and instructor, and the interaction between learners (Moore, 1989).

This model in turn allows us to unpack the community of inquiry model in terms of the nature of the three types of presence. For example, whilst cognitive presence might most obviously be seen in the relationship between learner and content, such presence might also be realised through the interaction between the learner and the instructor and through interactions between learners (Croxton, 2014). Teaching presence would most obviously be realised through the role of the teacher in the teaching and learning environment, but the nature of the role has been conceived in multiple and incommensurable ways (Dawson \& McWilliam, 2008). Finally, social presence could be realised in the relationship between the learners and in the relationship between the learner and the teacher. Questions about these three types of presence bring us much nearer to current questions about designing learning in terms of interaction types.

Bringing together the community of inquiry model and the three types of interaction model (Anderson, 2017) allows us to focus our questions about the potential utility of social media in education. We know that interactivity is an important factor for student learning and satisfaction, as well as persistence, in online learning environments (Croxton, 2014) and that, according to Miyazoe and Anderson (2013, 2015), putting the primary focus on any one of three types of interaction will lead to deep and meaningful learning.

Thus, presaging social interactions allows us to posit two hypotheses for this research: 
(1) Social media can be used to design learning that ensures that student-to-student interactions are at a high level; and

(2) Deep and meaningful formal learning will be supported as long as student-to-student interactions are at a high level.

There may be something counter-intuitive about the second hypothesis. For example, it might be argued that subject content is of primary importance because students need to engage with and master a body of knowledge as expressed in a set of learning outcomes. It might also be argued that the role of the teacher is crucial to student learning (Croxton, 2014) because the teacher plays a fundamental role in facilitating student learning.

However, we are not suggesting that the content and the teacher are unimportant. Rather, we are suggesting that deep and meaningful learning can be effectively facilitated by putting primary emphasis on student-tostudent interactions (Madland \& Richards, 2016). There is evidence to support this idea in terms of the thesis that deep and meaningful learning can occur if one of the three interaction types are at a high level (Miyazoe \& Anderson, 2013, 2015; Padilla Rodriguez \& Armellini, 2014). At the same time, “[a]ctive learning environments with high levels of interactivity between students and their environment (peers, instructors, and content) not only motivate students, but also improve overall learning achievement and satisfaction” (Croxton, 2014, p. 316).

It is not the purpose in this paper to provide a comprehensive review of the research around the models outlined above. Rather, we have sought to indicate what a future research direction might look like with respect to focusing on the utility of social media for engaging students with one another in order to improve student achievement and satisfaction. In this respect we can frame up two research hypotheses: firstly, that social media can be used to design learning that ensures that student-to-student interactions are at a high level, and secondly, that deep and meaningful formal learning will be supported as long as student-to-student interactions are at a high level. At the same time, and as detailed in the Findings section below, the utility of social media for teaching and learning is just one research direction amongst a range of others that emerged from the research.

\section{Methodology}

Our approach in this paper was driven by our shared research interests in social media in HE. What began as a number of corridor discussions around the pros and cons of using social media in HE culminated in a symposium for an Australasian educational technology conference, which provided an opportunity to take the pulse of specialists in the field on this very subject.

In order to achieve this, we submitted a proposal to conduct an old-fashioned debate. In essence, the structure involved five researchers taking on various roles, including debate moderator, to ensure that the discussion remained focused and that there was enough opportunity for audience participation, and two panel members on each side defending a research-based stance for either the affirmative (that social media use in HE for teaching and learning was a good thing) or the negative (that the use of social media for teaching and learning in HE was inherently bad). The debate also involved an overlay of Twitter and Periscope (a live streaming tool) to capture audience participation. Twitter participation took place throughout both the debate itself and audience participation time. Our aim was to access the breadth of opinion triggered by the debate in order to address our key question with regards to the use of social media in HE in Australasia - Where are we now? and thereby inform future enquiry or research as outlined above.

Using a debate as a springboard for discussion and the collection of data has been well regarded as a tool for exploring the construction of logics and communication skills for students (Vo \& Morris, 2006). Using a debate as a tool to gather research data is less common; however, it can be seen as a grounded form of data gathering (Creswell \& Poth, 2017) in that the debate itself was used to tease out themes that were prompted by broad questions, but were not explicitly drawn out in advance. Thus, our approach was to strategically use 
the debate in order to stage an environment where both sides of the arguments could be led, shared and built on with an engaged and experienced audience. The research team carefully crafted the arguments for both the affirmative and negative, based on existing literature, to ensure that the debate covered key areas of interest, concern and relevance. For this reason, we have also chosen to weave the literature review through the Debating the use of social media in HE - Findings section in this paper, rather than presenting it separately, for the aim was to prompt the audience to participate and contribute to a discussion reflective of multiple perspectives and reflect on these perspectives in an integrated manner.

“The Great Debate: Social Media Use in HE” (Willems, Adachi, McCluskey, et al., 2016) was conducted with the participation of an international audience on 28 November 2016 at the annual conference of the Australasian Society of Computing in Learning in Tertiary Education (ASCILITE) at the Adelaide Convention Centre. Approximately 150 conference delegates attended the hour-long session. In order to ensure informed participant consent, an initial announcement was made to inform audience members that the debate was going to be streamed live, recorded and potentially used for a subsequent research opportunity through its data analysis. The participants were invited to leave the room or not to participate in the social media discussion if they had any concerns. Ethics approval was granted by Deakin University to analyse the publicly available material in both the Periscope video capture and the Twitter feeds (reference number: 2017-042).

The participants in this study were firstly self-selecting, and secondly, they were participating in a conference about educational technology in HE, both of which shaped the data collected to an important extent. This specific cohort was therefore likely to be relatively positive and excited about the potential of social media in HE. Regardless of these limitations, it is still valuable to analyse the data in terms of the key themes and concerns that were raised in this context, as these participants can be seen as representative of those who drive innovation as it relates to social media use in HE in Australasia.

Audience participation in the debate was robust both from the floor - as captured by the live Periscope feed and via the Twitter handle (\#ascilite2016dbt). In total, 63 tweets were contributed, using the debate hashtag provided. These were collated and analysed for this paper. In addition, the session was broadcast in real time and recorded with Periscope (https://www.periscope.tv/w/1MYGNOnqLYRJw), which presented an opportunity for global participants to contribute to the debate as well. A total of 72 live viewers in real time were recorded on the day of the debate, and its recording continued to raise further hits after the event with 219 views observed as at 16 June 2017.

Following transcription of the data sources (live Periscope recording and tweets posted on the Twitter feed), a process of thematic analysis took place to capture emergent ideas. This thematic analysis of the qualitative responses followed the six-phase recursive process for thematic analysis (Braun \& Clarke, 2006; Clarke \& Braun, 2013a): an initial familiarisation with the data, followed by coding, searching for themes, reviewing themes, and defining and naming themes. Finally, the process involved the writing up of these findings by "weaving together the analytic narrative and (vivid) data extracts to tell the reader a coherent and persuasive story about the data, and contextualising it in relation to existing literature” (Clarke \& Braun, 2013b, p. 121).

Due to the relatively small size of the data set, the transcripts were hand coded. The initial coding process was inductive in that it was guided by what was evident in the data itself. In the first round of coding, both data sources (Periscope transcription and the Twitter feed) were treated separately.

The initial set of coding of the Twitter data revealed contributions that fell into the following themes: what is social media?; social media in HE; institutional lag; staff professional development; pedagogy; social media policy; public versus private realms; formal learning and training of students versus personal and/or informal learning; digital natives; bullying/inappropriateness; personal learning environment vs learning management system (LMS); student empowerment; digital literacy; and personal experiences teaching with social media.

The initial coding of the Periscope transcript identified an overlapping set of initial themes: promoting informal learning opportunities; equity and ethical considerations; social media policy; lifelong learning; 
benefits of other social media (LinkedIn); beyond the LMS; disruptive and subversive media; student selfempowerment; academic workloads; teaching skills for the world; and guidance for students on moving from closed to open societies.

In the subsequent processes of reviewing and naming the themes, five higher level themes were identified and both data sets were allocated to these accordingly. The final five themes are institutional lag, social media policy, pedagogy, staff professional development, and digital literacy.

\section{Debating the use of social media in HE - Findings}

In this section, we present the key ideas that emerged from the analysis of the qualitative participation in the debate: verbally from the audience as captured by the Periscope feed, and in text and images captured from the Twitter feed, interwoven with some of the literature presented as part of the debate itself (Clarke \& Braun, 2013b). The resulting analysis represents the current perspectives of academics and educational technology specialists working in HE, who are mostly located in Australasia. To contextualise these responses, we begin with a summation of the main arguments put forward by the affirmative and negative representatives during the debate.

Analysis of the Twitter feed and verbal comments from the floor captured in Periscope generally reflects the perceived tensions captured in the above debate, which can broadly be identified as social and pedagogical possibilities, and institutional risks. Arguably, the latter arises from the reluctance of institutions to develop and implement firm policies and processes that address social media. This institutional lag featured prominently in our contributions, but pedagogical possibilities were also emphasised - with caveats surrounding issues of equity and widening, as opposed to increasing, participation (Selwyn, 2016). Similarly, student-led learning and digital literacy were mentioned as a strong benefit of social media use with both staff and students benefitting from an increased focus on building skills and digital identities. All of this demonstrated simultaneously the risks of not developing a sustained and anticipatory approach to social media that addresses their potential pedagogically, socially and strategically.

The overarching argument in favour of the use of social media in HE, or at least in favour of considering its potential benefits for student learning, lies in the recognition that social media are part of everyday social life for most students (Cowling, 2017). At the same time students are making use of social media for their learning (Smith, 2017). Ignoring these facts could effectively create an artificial boundary between HE institutions and the society of which they are a part. This may already be happening with the use of social media by academics for teaching and learning lagging behind the more general use of social media (Manca \& Ranieri, 2016; Seaman \& Tinti-Kane, 2013). Thus, the arguments in favour of social media use in HE in this section all flow from this fundamental umbrella argument and are from both student and staff perspectives.

Thus, we have essentially an argument in favour of the social utility of connectedness - meeting students where they are at (Kift, Nelson, \& Clarke, 2010; Nelson \& Clarke, 2014; Smith, 2017), developing digital literacy (Seaman \& Tinti-Kane, 2013) and critical thinking skills (Barnett, 2015; Bruns, 2010), and engaging students (Kumar Sharma, Joshi, \& Sharma, 2016) through new pedagogical approaches designed to leverage the affordances of social media (Trowbridge, Waterbury, \& Sudbury, 2017).

In many ways, this perspective situates social media as a potential solution to a variety of challenges associated with mass education in a digital age, including issues related to equity and social justice (Corn, 2013; Thomas, 2013), transition (Hall \& Maugham, 2015) and re-engagement (Piotrowski, 2015;). Moreover, the role of social media in building digital agency and identity, whilst still nascent in terms of scholarship (Connelly \& Osborne, 2015), offers potential for the development of graduate capabilities, and personal and professional growth (Weiner, 2016). Central to this perspective, therefore, are social issues, rather than institutional matters of governance and policy to guide the use of social media and to reduce risks to both the individuals using social media and the institutions within which social media are being used to facilitate the teaching and learning process. This raises a series of questions: How do we ensure the university retains 
contemporary credibility? How do we ensure learning keeps up with offerings from the private sector? How do we connect with students and each other in increasingly complex environments?

By contrast, our alternative perspective presents an institutionally driven view focused on policy (Cronin, 2017) and operational issues, including the costs, risks and benefits associated with adopting new and perhaps unpredictable technologies. How do we maintain control of commercially based technologies? How do we protect ourselves from litigation? How do we protect our students from breaches of privacy? How do we manage new technologies when we cannot anticipate their consequences? And how do we fund the necessary change management associated with new technology adoption? (Stahl, Sharplin, \& Kehrwald, 2016). Policy and processes loom large here, as does the important question of whether the costs and risks of new technology will equal the benefits for universities in the demand-driven age. In other words, will the trouble it takes to adopt new technologies result in more enrolments, a better quality experience, improved learning outcomes, and/or higher retention rates? (Balakrishnan, Teoh, Pourshafie, \& Liew, 2017). Here, the politics and economics of mass education are clearly evident: increasing competition across the sector, growing levels of participation across the social strata, complex regulation, and measurement processes that track retention rates whilst simultaneously measuring standards.

\section{Institutional lag}

HE institutions have been, at best, slow and fairly pedestrian in their adoption of digital media. As others have argued (Malikowski, 2008; Malikowski, Thompson, \& Theis, 2006) current platforms such as LMSs remain underutilised, which was reflected in comments from the floor, particularly the following one, which drew cheers and applause from the audience: "poor LMS design is a big hurdle in connecting with students" (via Persicope capture). Interestingly, both Periscope and Twitter feeds indicate that educational technology professionals see universities as lagging when it comes to digital affordances. In contemporary environments, this is a problem: "institutions need to move with the times, maybe they need to make an effort to figure out what they can do \& how?” (via Persicope capture).

The result of this institutional lag is a perception that "our institutions are not ready...will they ever be?” (via Twitter feed). In contemporary discourses around disruptive technologies, this turgid response to rapidly changing digital environments can be seen as perilous:

[Social media] is going to be an important part of lifelong learning and if we think about how the university sector is being disrupted more and more, it could be that degrees and qualifications as we know them might not be there in the next ten years. It might be that students get micro-qualifications and then stitch those together, and then in the meantime, go out and do informal learning online. And we've got to prepare our students for that possibility. (via Persicope capture)

In part, we might argue that this reluctance to embrace social media arises from resistance to change and a "firming of the barricades" from within the academy, as argued by Barnett (2011) and others. Grayling's (2015) analysis of social change certainly affirms this, with slow take-up being seen as the by-product of survivalist instincts. Certainly, perceptions of institutional lag as a result of gatekeeping instincts is present in the Twitter data: "so should we send academics back on the stage behind the lectern so we keep control?” (via Twitter feed). However, this may only be part of the picture with many universities actively strategising to meet possible future developments.

\section{Social media policy}

Whatever the reasons for the perceived lag in the adoption of social media affordances, there is a heightened awareness of a lag in the development of policies, both in the data presented here and in the literature (Willems, Adachi, \& Grevtseva, 2016). One Persiscope contributor noted the perils of delaying policies surrounding disruptive technologies: 
Of the twenty-five universities only three have social media policies, and I can tell you with the latest events in South Africa, they are all busy crafting social policies for both staff and students. When we talk about disruption, I'm saying careers can be made and broken by [social media]. (via Periscope capture)

This highlights the double risk of both ignoring and adopting social media: "if the risk of social media use is the main concern, putting your head in the sand and hoping it goes away wont [sic] help” (via Twitter feed). Rather, “[d]eveloping social media policies can help the disruptive side of social media” (via Twitter feed), which might consolidate any strategic advantages thereby attained.

Straddling both organisational and reputational concerns, policy writing around social media raises some very interesting questions about identity and governance as one contributor pointed out: "where does the "institution" start \& where does individual responsibility end??" (via Twitter feed).

Those media flurries wherein academics are profiled as a result of social media comments highlight this (e.g., Joyner, 2016), and it is perhaps here that policy writing work begins. In addition, the move towards incorporating social learning within LMSs and other similar platforms (such as FutureLearn), suggests there may be some urgency in developing appropriate policies: "Struggle for LMS to embrace/include open, social tools is the biggy for policy writing” (via Twitter feed).

However, while some commented on the lack of policy or not clearly defined social media policy, there were also examples offered of institutions working hard to update and make their social media policies relevant to the changing world:

We are in the process of developing [a social media policy] ... We feel it is better to educate and mitigate the risks that way than to cut off social media completely because it is going to be an important part of lifelong learning... (via Periscope capture)

Perhaps the real issue is instead instituting and managing clear and easily understandable policy in a way that makes social media use practicable, rather than a barrier in itself.

\section{Pedagogy}

Despite an absence of comprehensive social media policies, many educators are harnessing social media and adapting their teaching and learning to better connect and engage their students. As one colleague stated: "why wait for the institution?? if you are ready and enthusiastic then the students will be too" (via Twitter feed). Another commented: "Engagement is a key reason and is part of education in higher institution" (via Twitter feed). Many avenues are used - not only those potential social networks within their respective LMSs, but also a host of other social media tools such as Twitter, Padlet, YouTube, Tumblr, or Blogger to both connect students and engage them in the production and consumption of media artefacts.

On a pedagogical level, the main attraction and potential of social media lies in the sense that they are almost naturally aligned with social constructivist pedagogies, or “'friending' Vygotsky”, as Churcher, Downs, and Tewksbury (2014) put it. Thus, the potential of social media lies in the idea of meeting students where they are at, and thereby establishing learning communities in which the co-construction of knowledge can easily be facilitated (Dron \& Anderson, 2014; Ralph \& Ralph, 2013). Ideally, social media allow for student-centred active learning approaches based on participation and engagement and are grounded in the pedagogical notion of Vygotsky's zone of proximal development (Saxena, 2017). Despite this potential, some have a more cautionary approach and warn that pedagogy as a driver of learning design often gets lost (Salomon, 2016).

In recognising the pedagogical possibilities of social media, one commentator underlined the importance of distinguishing between the ways in which social media applications and services are used. While we had initially noted in the introduction to the debate that social networks were but one form of social media (via 
Periscope capture), this had not been clearly enough articulated within the debate proper. As a result, the two terms were conflated at times:

You've blended social media and social networks. And they are two different things. Social media...the focus is on what you post and the conversations around that, whereas social networks are around the connections you make and the conversations you have. So I think it's important to make that distinction...And to make sure that it is fit for purpose, because it is not always. (via Periscope capture)

This point is well taken, in that the distinction must frame pedagogical approaches to teaching and learning in digital environments if they are to serve their purposes effectively. Certainly, production and consumption are straddled across both social networks and media:

[Students] create blogs and websites, and videos, and infographics and they curate collections on social media. My rationale for this is that they need to learn about Web 2.0 environments and they need to teach their own students about becoming curators and creators, rather than being passive consumers. (via Periscope capture)

This demonstrates an awareness of pedagogical practices that are focused on developing digital skills; however, there are also approaches to student engagement divorced from teaching and learning, for example, alumni networking:

So far all we have mentioned is Facebook. We haven't talked about LinkedIn and the opportunities that exist in private closed groups there for you to bring in outside expertise. For you to bring in your graduates to work with your undergraduates, or your alumni to work with your students. (via Periscope capture)

While discussions regarding pedagogical approaches per se were limited, perhaps a natural result of the different foci of the debate, one topic to receive attention was staff professional development.

\section{Staff professional development}

During the debate, the importance of staff professional development in and around the use of social media in HE was raised. Highlighting the urgency of this issue among those present (physically and virtually) were the following sample comments: "Academic staff require more support / training / time in using social media platforms" (via Twitter feed), and "eLearning will only change when we change the way we teach" (via Twitter feed). In this context, one might argue that there is a clear requirement for institutions to embed social media and social networking in teaching and learning, supported with sustained and scalable professional development for staff: "the biggest con in using social media for highered [sic] is when it's used badly by academics or is just an afterthought”. (via Twitter feed).

Attention must also be given to weighing up the benefits and costs of embarking on what can only be seen as a change management process of sizeable proportions. What would be the benefits and what are the risks in evidence? For, as Selwyn (2014) has repeatedly pointed out, whilst there is often a strong perception that technology is a quick fix for issues pertaining to HE, the quick fix generally results in a host of unexpected problems arising from the introduction of the new technology itself.

Essentially, the key question in this context is whether or not we spend time developing pedagogies and developing staff capacity or leave social media and social networking as an organic expression of student social learning. In other words, is it better to just let social media use run its course, without bothering to devise cumbersome policies that are unlikely to keep up with social media and social networking anyway? Or must we fully embrace what is a fluid and socially grounded aspect of the contemporary digital world? "Should social media be used in education? I don't think it's our decision, empowered students will use it if they choose" (via Twitter feed). 
Interestingly, one aspect of the debate was an awareness of social media as a naturally entrenched aspect of distributed learning (Lea \& Nicoll, 2002). “All [of] us learn through diverse channels” (via Twitter feed) one commentator remarked, with another identifying the blurred divisions between formal and informal learning "The students PLE [personal learning environment] is significant to their learning...this is driven by their social media" (via Twitter feed). Whether or not social media does in fact drive learning is a matter for research, as there is currently no evidence for this. However, there is some evidence that social learning does, and with positive results (Eid \& Al-Jabri, 2016). In recognition of this, one contributor's comment on the power of social learning saw the LMS as a prime example of missed opportunity:

As institutions, we are partly to blame in providing [students] with learning management systems that are deficient in social learning tools...so I think as institutions, we need to recognise that our students are going to be using social media anyway...I think we need to recognise that social media is a part of education, whether we like it or not. What should we do about that? (via Periscope capture)

This comment clearly captures the reality of the situation versus espoused rhetoric. Social media is here; it is being used for teaching and learning in $\mathrm{HE} \mathrm{-} \mathrm{whether} \mathrm{we} \mathrm{like} \mathrm{it} \mathrm{or} \mathrm{not} \mathrm{-} \mathrm{and} \mathrm{so} \mathrm{the} \mathrm{real} \mathrm{concern} \mathrm{is} \mathrm{how} \mathrm{to} \mathrm{best}$ manage this. One clear way, as the next section explores, is to consider a means by which we can teach others how to best work in these public arenas.

\section{Digital literacies}

Perhaps the strongest element arising from contributors was the belief that social media represented an opportunity to develop digital literacies. Developing digital literacies is a key graduate outcome for many institutions, if often misunderstood both in practice and in the literature (Lea \& Jones, 2011). Based on the recent criticism around narrow definitions of digital literacy traditionally driven by "critical consumption of digital forms” (Pangrazio, 2016, p. 164), new frameworks recognise more of the creative and social-cultural aspects of digital literacies. The NMC Horizon Report (Johnson et al., 2016) therefore proposes a multifaceted plurality, incorporating three elements: universal literacy (e.g., using basic digital tools), creative literacy (e.g., creating richer content with digital ethics and copyright knowledge), and literacy across disciplines (e.g., discipline/context specific application of digital media).

Our contributors recognised social media as a reflexive tool offering the potential for empowerment and skills to enhance agency in a world enveloped by the digital (Floridi, 2014). As one noted:

I feel that I'm empowering my students to be in a community where they can operate outside of me and outside of the university and be empowered to do that. So it's an "empower and manage" approach, rather than a more guarded approach [to teaching and learning]. (via Periscope capture)

Learning opportunities were seen as rife, particularly in preparing students for ethical contributions to society, with the university charged with guiding students in the development of their digital literacies "from 'closed' societies to open, public content contributions?” (via Twitter feed), and in this way allowing them to learn in safer environment: "maybe students making and getting called out on inappropriate tweets is a good thing so they learn \& understand why that is” (via Twitter feed).

In addition, there is an awareness that digital literacies are increasingly important in contemporary society, with new challenges at both the public and private level. The attention given to the ways in which social media can drive public debate and influence political outcomes is a case in point here, with much made in recent times of this powerful new influence (Bruns, 2016). Thus, one contributor pointed out that "Recent fake news scandals on [Facebook] underline the need for teachers to lead the way in digital literacies using SM" (via Twitter feed). This reinforces Barnett's (2011) argument for the ecological university in which it is the social responsibility of the university to develop critically aware graduates who will in turn enhance 
society through agency, reflexivity and critical capacities. Certainly, this reinforces the general notion that universities need to take social media seriously, because as one contributor commented, "If we engage with social media we have the opportunity to help our students become digitally literate” (via Twitter feed).

\section{Towards a research agenda}

Given the context and the audience, the debate was always going to yield potentially valuable insights into the use of social media in HE and, as we have seen, this turned out to be the case with themes emerging that extended beyond teaching and learning questions per se and into, for example, questions about institutional policies on the use of social media in HE and related institutional lag. Thus, whilst we retain a commitment to our original research hypotheses, the range of themes identified suggests multiple research directions. These multiple directions can be broadly categorised with respect to the barriers and enablers for the pedagogically sound use of social media in teaching and learning. This extends well beyond the research focus identified above - engaging students through presaging social interactions in teaching and learning - and extends into, for example, the challenges with respect to effecting change in academic cultures (Shen \& Tian, 2012). In this context, we might explore the difference between piecemeal change and systemic change that aims to transform, for example, institutional teaching and learning cultures. In this context, the importance of developing staff capability in the use of social media to enhance teaching and learning becomes foregrounded, as well as their motivation to do so. There are, then, multiple avenues for future research.

Our debate clearly contributes to the idea that the incorporation of social media in learning and teaching ought to advance student learning and capability rather than simply being incorporated for the sake of appearances and promotional benefits at the institutional level. If we agree with the primacy of graduate employability, then the question becomes whether it is possible to design learning opportunities that are going to effectively integrate social media into learning activities and assessments in ways that are authentic, for example, in ways in which social media would be used in the workplace (Kek \& Huijser, 2017). The acid test is whether a student who has engaged with social media, and who is a confident "produser" (Bruns, 2010) of social media, would be more employable than a student who has not. If the answer is no, then one would have to ask why we would put time and effort into it, rather than adopting a hands-off approach.

Arguably, however, it is also important to consider a number of other capabilities that potentially enhance or influence the lives of our graduates and the possible futures of our societies - capabilities that extend beyond employment and, as Arvanitakis and Hornsby (2016, p. 1) argue, work towards fostering students who care "not only about gaining information and generating knowledge but [are] rooted in the reality of their context, problem oriented and interested in applying their knowledge for the betterment of a society". This includes fostering a number of digital literacies that extend beyond the workplace into personal and civic agency and critical readings of social media. What is particularly evident in the data is the elevation of digital literacies as a key potential benefit in the use of social media, aligned with an institutional emphasis on graduate employability. However, there is also a civic role, with multiple tweets commenting on the hazards of cyberbullying and the importance of netiquette. Regardless, there is clearly a perception within the industry that HE policies are not abreast of current student behaviours, and of teaching and learning practices. In this regard, the social and civic purpose of the university is elevated beyond its traditional role as a centre for the advancement of knowledge (Barnett, 2015).

This then relates back to the problems discussed above around the lack of clear institutional policies guiding the use of social media for learning and teaching. If the incorporation of social media, along with the elevation of digital literacy and critical thinking, is a prerequisite in the development of 21st century futureproofed citizens and lifelong learners, then related teaching practices and graduate outcomes and capabilities should be guided by an appropriate set of policies or at least good practice guidelines. Teaching staff, who are at the forefront of engaging in contested social media spaces with students where their practice and professionalism are at stake, are potentially at risk. There have been cases of academics being disciplined, or even expelled, based on their misconduct for offensive or misuse of social media in a university context. In other words, the boundaries between private and public, and between leisure and professional spaces, can be ambiguous, and clear policy and guidelines would go some way in addressing such ambiguity. In addition, 
there is scope for professional development opportunities where academics may explore opportunities and challenges related to social media (Willems, Adachi, \& Grevtseva, 2016). Policy consequently sets the institutional boundaries within which academics may feel safe and guided in experimenting with new ideas. This is important, for as Manca and Ranieri (2016, p. 218) note, "the higher the perceived risk of using social media, the less likely faculty uses the technology to support in-class instructions frequently", and risk can be managed by clear policy guidelines. This would pave a smooth passage for the many good practice examples that incorporate social media in learning and teaching in innovative ways (Trowbridge et al., 2017).

While there still appears to be a lack of adequate or appropriate social media policies in the Australian HE context, particularly as they relate to learning and teaching, there are some examples of social media policies in the United States HE context. One example is Washington University in St Louis (2012); its social media policy states the following:

The following [social media] policy serves as a guideline and starting point for those initiating a social media feed that involves the university, its schools, departments, programs, groups, organizations and individuals. It is also a reference for those managing existing feeds, so that the university's efforts in social media communications are as consistent as possible.

This appears to be fairly typical and is clearly very broad and related to the complete range of social media use across the institution, rather than specifically focused on social media for learning and teaching. In recognition of this apparent scarcity of clear and focused social media policies, the Universities and Colleges Information Systems Association in the United Kingdom has designed a social media toolkit (2015), which can be used as a reference point in the development of social media for learning and teaching policy. In the Australian HE context, the Office for Learning and Teaching (http://www.olt.gov.au/) projects would be the most obvious place to look for practice related to social media for learning and teaching, but there appears to be very little available in this respect. As Seaman and Tinti-Kane (2013, p. 3) have noted about academic staff adopting social media:

Concerns about privacy, both for themselves and for their students, and about maintaining the class as a private space for free and open discussion, have been at the top of the list of concerns in all of the reports. Until faculty feel that this issue has been addressed, the wide-scale adoption of commercial social media tools in the classroom will remain limited.

Again, this draws attention to the need for clear policy, as the lack thereof has the potential to constrain academic staff, which in turn has the potential to disadvantage students in ways identified above.

\section{Conclusion}

Like it or not, social media are part of the global landscape, including HE. This paper has captured the debate of the pros and cons, reinforced by the tricky problems experienced by those working in academia. It has explored the implications of this debate and makes suggestions for ways forward.

Rather than trying to reign in a galloping horse, we need to consider and develop ways of fostering and leveraging the advantages. Aspects considered to achieve this include providing clear and straightforward policies so as not to be an impediment; considering the impact of institutional lag; continuing professional development of staff; and developing digital literacies as a key student graduate capability in the digital world; and evaluating underlying pedagogies.

We thus call for targeted research on this topic. Our own data collection has drawn from a specific audience (noted as a limitation), which would have skewed the results to some extent, as noted in the Methodology section. It would therefore be worthwhile to compare these data with broader perspectives gathered across the HE sector. Furthermore, the data presented here are in many respects based on opinions and perceptions, rather than hard data-driven evidence of the success or otherwise of pedagogical applications of social media 
use in learning and teaching. Thus, we identify a need here to test applications of pedagogical social media on a large scale across different institutions and across Australasia. This could for example include developing the Vygotskyan theoretical framework (Churcher, Downs, \& Tewksbury, 2014) in more depth and then applying it to specific case studies to ascertain whether either the potential being promoted on the one hand, or the cautious attitudes towards social media use in HE on the other, are actually warranted and to what extent. The value and scope of this particular research project has been an opportunity to map out and analyse the key themes and concerns as perceived by a cohort that can be seen as being at the cutting edge of technological innovation in learning and teaching in $\mathrm{HE}$ in the specific context of Australasia. In a sense then, this is an exploratory study, which has mapped out a potential research trajectory for the near future.

\section{References}

Aichner, T., \& Jacob, F. (2015). Measuring the degree of corporate social media use. International Journal of Market Research, 57(2), 257-275. https://doi.org/10.2501/IJMR-2015-01

Anderson, T. (2017, September). How communities of inquiry drive teaching and learning in the digital age. Retrieved from https://teachonline.ca/sites/default/files/pdf/enewsletters/how_communities_of_inquiry_drive_teaching_and_learning in the digital.pdf

Arvanitakis, J., \& Hornsby, D. (Eds.). (2016). Universities, the citizen scholar and the future of higher education. New York, NY: Palgrave Macmillan.

Au, M., Lam, J., \& Chan, R. (2015). Social media education: Barriers and critical issues. In K. C. Li, T. L.Wong, S. K. Cheung, J. Lam, \& K. K. Ng (Eds.), Technology in education: Transforming educational practices with technology (pp. 199-205). Berlin: Springer.

Balakrishnan, V., Teoh, K. T., Pourshafie, T., \& Liew, T. K. (2017). Social media and their use in learning: A comparative analysis between Australia and Malaysia from the learners' perspectives. Australasian Journal of Educational Technology, 33(1), 81-97. https://doi.org/10.14742/ajet.2469

Barnett, R. (2011). Being a university. London: Routledge.

Barnett, R. (2015). Understanding the university: Institution, idea, possibilities. London: Routledge.

Braun, V., \& Clarke, V. (2006) Using thematic analysis in psychology. Qualitative Research in Psychology, 3(2), 77-101. https://doi.org/10.1191/1478088706qp063oa

Bruns, A. (2010). Distributed creativity: Filesharing and produsage. In S. Sonvilla-Weiss (Ed.). Mashup cultures (pp. 24-37). Vienna: Springer.

Bruns, A. (2016, November 23). Echo chamber? What echo chamber? The Conversation. Retrieved from https://theconversation.com/echo-chamber-what-echo-chamber-69293

Churcher, K., Downs, E., \& Tewksbury, D. (2014). “Friending” Vygotsky: A social constructivist pedagogy of knowledge building through classroom social media use. The Journal of Effective Teaching, 14(1), 3350. Retrieved from https://www.uncw.edu/jet/articles/Vol14_1/Churcher.pdf

Clarke, V., \& Braun, V. (2013a). Successful qualitative research: A practical guide for beginners. London: Sage.

Clarke, V., \& Braun, V. (2013b). Teaching thematic analysis: Overcoming challenges and developing strategies for effective learning. The Psychologist, 26(2), 120-123.Retrieved from https://thepsychologist.bps.org.uk/volume-26/edition-2/methods-teaching-thematic-analysis

Connelly, L., \& Osborne, N. (2015, December). Student identities in transition: Social media experiences, curation and implications for Higher Education. Paper presented at the Social Media for Learning in Higher Education Conference 2015, Sheffield, United Kingdom. https://doi.org/10.7190/SocMedHE/2015/7

Corn, A. (2013). Introduction: The Indigital revolution. In L. Ormond-Parker, A. Corn, C. Fforde, K. Obata, \& S. O’Sullivan (Eds.), Information technology and Indigenous communities (pp. 1-8). Canberra: AIATSIS Research Publications.

Cowling, D. (2017, February 1). Social media statistics Australia - January 2017. SocialMediaNews. Retrieved from https://www.socialmedianews.com.au/social-media-statistics-australia-january-2017/

Creswell, J. \& Poth, C. (2017). Qualitative inquiry and research design: Choosing among five approaches (4th ed.). London: Sage.

Cronin, G. (2017). Some good examples of social media policies [Blog post]. Cardies and Tweed. Retrieved 
from https://cardiesandtweed.files.wordpress.com/2014/10/more-social-media-policies.pdf

Croxton, R. (2014). The role of interactivity in student satisfaction and persistence in online learning. Journal of Online Learning and Teaching, 10(2), 314-325. Retrieved from http://jolt.merlot.org/vol10no2/croxton_0614.pdf

Dabbagh, N., \& Kitsantas, A. (2011). Personal learning environments, social media, and self-regulated learning: A natural formula for connecting formal and informal learning. The Internet and Higher Education. https://doi.org/10.1016/j.iheduc.2011.06.002

Dawson, S., \& McWilliam, E. (2008). Investigating the application of IT generated data as an indicator of learning and teaching performance. Sydney: Australian Learning and Teaching Council.

Dron, J., \& Anderson, T. (2014). Teaching crowds: Learning and social media. Edmonton: Athabasca University Press.

Eid, M. I., \& Al-Jabri, I. M. (2016). Social networking, knowledge sharing, and student learning: The case of university students. Computers \& Education, 99, 14-27. https://doi.org/10.1016/j.compedu.2016.04.007

Facer, K.L. (2011). Learning futures: Education, technology and social change. New York, NY: Routledge.

Floridi, L. (2014). The 4th revolution: How the infosphere is reshaping human reality. Oxford: Oxford University Press.

Grayling, A. C. (2015). The challenge of things: Thinking through troubled times. London: Bloomsbury Publishing.

Hall, L., \& Maugham, C. (2015). Going where the students are already: Reimagining online learning where students and lecturers co-create an interactive teaching and learning space. The International Journal of Technologies in Learning, 22(3), 51-61. Retrieved from http://ijltl.cgpublisher.com/product/pub.262/prod.96

Johnson, L., Adams Becker, S., Cummins, M., Estrada, V., Freeman, A., \& Hall, C. (2016). NMC Horizon Report: 2016 Higher education edition (0989733556). Austin, TX: The New Media Consortium. Retrieved from http://cdn.nmc.org/media/2016-nmc-horizon-report-he-EN.pdf

Joyner, T. (2016, June). It's uni brand vs personal stand in social media's grey area. The Australian. http://www.theaustralian.com.au/higher-education/its-uni-brand-vs-personal-stand-in-social-mediasgreyarea/news-story/0fa55882d1b75c2e81a3a2a2002aed53

Junco, R., Heiberger, G., \& Loken, E. (2011). The effect of Twitter on college student engagement and grades. Journal of Computer Assisted Learning, 2, 119-132. https://doi.org/10.1111/j.13652729.2010.00387.x

Kaplan, A. M., \& Haenlein, M. (2010). Users of the world, unite! The challenges and opportunities of social media. Business Horizons, 53(1), 59-68. https://doi.org/10.1016/j.bushor.2009.09.003

Keen, A. (2007). The cult of the amateur. London: Nicholas Brealey Publishing.

Kek, M. Y. C. A., \& Huijser, H. (2017). Problem-based learning into the future: Imagining an agile PBL ecology for learning. Singapore: Springer.

Kift, S., Nelson, K. \& Clarke, J. (2010). Transition pedagogy: A third generation approach to FYE - A case study of policy and practice for the higher education sector. The International Journal of the First Year in Higher Education, 1(1), 1-20. https://doi.org/10.5204/intjfyhe.v1i1.13

Kumar Sharma, S., Joshi, A., \& Sharma, H. (2016). A multi-analytical approach to predict the Facebook usage in higher education. Computers in Human Behavior, 55, 340-353. https://doi.org/10.1016/j.chb.2015.09.020

Lea, M. R., \& Jones, S. (2011). Digital literacies in higher education: Exploring textual and technological practice. Studies in Higher Education, 36(4), 377-393. https://doi.org/10.1080/03075071003664021

Lea, M. R., \& Nicoll, K. (2002), Distributed learning: Social and cultural approaches to practice. London: Routledge.

Macfarlane, B. (2015). Student performativity in higher education: Converting learning as a private space into a public performance. Higher Education Research \& Development, 34(2), 338-350. https://doi.org/10.1080/07294360.2014.956697

Madland, C. \& Richards, G. (2016). Enhancing student-student online interaction: exploring the study buddy peer review activity. International Review of Research in Open and Distributed Learning, 17(3). Retrieved from ERIC database. (EJ1102718)

Malikowski, S. (2008). Factors related to breadth of use in course management systems. The Internet and Higher Education, 11(2), 81-86. https://doi.org/10.1016/j.iheduc.2008.03.003 
Malikowski, S., Thompson, M., \& Theis, J. (2006). External factors associated with adopting a CMS in resident college courses. The Internet and Higher Education, 9(3), 163-174. https://doi.org/10.1016/j.iheduc.2006.06.006

Manca, S., \& Ranieri, M. (2016). Facebook and the others. Potentials and obstacles of social media for teaching in higher education. Computers \& Education, 95, 216-230. https://doi.org/10.1016/j.compedu.2016.01.012

Miyazoe, T., \& Anderson, T. (2013). Interaction equivalency in an OER, MOOCS and informal learning era. Journal of Interactive Media in Education, 2. https://doi.org/10.5334/2013-09

Miyazoe, T., \& Anderson, T. (2015). Interaction equivalency in the OER and informal learning era. European Journal of Open, Distance and E-Learning, 18(2), 94-104. Retrieved from http://www.eurodl.org/index.php?p=special\&sp=articles\&inum=7\&article=695

Moore, M. (1989). Editorial: Three types of interaction. American Journal of Distance Education, 3(2), 1-7. https://doi.org/10.1080/08923648909526659

Nelson, K., \& Clarke, J. (2014). The First Year Experience: Looking back to inform the future. HERDSA Review of Higher Education, 1, 23-45. Retrieved from http://www.herdsa.org.au/herdsa-review-highereducation-vol-1/23-45

Padilla Rodriguez, B., \& Armellini, A. (2014) Applying the interaction equivalency theorem to online courses in a large organization. Journal of Interactive Online Learning, 13(2), 51-66. Retrieved from http://www.nclor.org/issues/jiol/v13/n2/3

Pangrazio, L. (2016). Reconceptualising critical digital literacy. Discourse: Studies in the Cultural Politics of Education, 37(2), 163-174. https://doi.org/10.1080/01596306.2014.942836

Piotrowski, C. (2015). Emerging research on social media use in education: A study of dissertations. Research in Higher Education Journal, 27, 1-12. Retrieved from http://www.aabri.com/manuscripts/142097.pdf

Ralph, M. \& Ralph, L. (2013). Weapons of mass instruction: the creative use of social media in improving pedagogy. Issues in Information Science and Information Technology, 10, 449-460. https://doi.org/10.28945/1821

Rourke, L., Anderson, T., Garrison, D.R., \& Archer, W. (1999). Assessing social presence in asynchronous text-based computer conferencing. Journal of Distance Education, 14(2), 50-71. Retrieved from http://www.jofde.ca/index.php/jde/article/view/153

Salomon, G. (2016). It's not just the tool but the educational rationale that counts. In E. Elstad (Ed.). Educational technology and polycontextual bridging (pp. 149-161). Rotterdam: Sense Publishers.

Saxena V. (2017). Participation, produsage, and pedagogy: Social media as a tool to enhance teaching and learning experience. In S. Tang \& S. Cheah (Eds.), Redesigning learning for greater social impact (pp. 223-237). Singapore: Springer.

Seaman, J., \& Tinti-Kane, H. (2013). Social media for teaching and learning. Boston, MA: Pearson.

Selwyn, N. (2014). Digital technology and the contemporary university: Degrees of digitization. New York, NY: Routledge.

Selwyn, N. (2016). Is technology good for education? Cambridge: Polity Press.

Shen, X., \& Tian, X. (2012). Academic culture and campus culture of universities. Higher Education Studies, 2(2). https://doi.org/10.5539/hes.v2n2p61

Smith, E. (2017). Social media in undergraduate learning: categories and characteristics. International Journal of Educational Teachnology in Higher Education, 14(1), 1-12. https://doi.org/10.1186/s41239017-0049-y

Stahl, G., Sharplin, E., \& Kehrwald, B. (2016). Developing pre-service teachers’ confidence: real-time coaching in teacher education. Reflective Practice, 7(6), 724-736. https://doi.org/10.1080/14623943.2016.1206882

Thomas, L. (2013). What works? Facilitating an effective transition into higher education. Widening Participation and Lifelong Learning, 14, 4-24. https://doi.org/10.5456/WPLL.14.S.4

Trowbridge, S., Waterbury, C., \& Sudbury, L. (2017, April). Learning in bursts: Microlearning with social media. Educause Review. Retrieved from http://er.educause.edu/articles/2017/4/learning-in-burstsmicrolearning-with-social-media

Universities and Colleges Information Systems Association. (2015). Social media toolkit: A practical guide to achieving benefits and managing risks. Oxford: Author. 
Vo, H. X., \& Morris, R. L. (2006). Debate as a tool in teaching economics: Rationale, technique, and some evidence. Journal of Education for Business, 81(6), 315-320. https://doi.org/10.3200/JOEB.81.6.315-320

Washington University. (2012). Social media policy. Retrieved from https://wustl.edu/about/compliancepolicies/media-policies/social-media-policy/

Weiner, W. (2016). The influence of social media on job seekers in the digital age. Career Planning and Adult Development Journal, 32(3), 26-31. Retrieved from https://www.questia.com/library/journal/1P34171122281/the-influence-of-social-media-on-job-seekers-in-the

Willems, J., Adachi, C., \& Grevtseva, Y. (2016). Working with social media in tertiary education: A contested space between academics and policies. In S. Barker, S. Dawson, A. Pardo, \& C. Colvin (Eds.), Show Me the Learning. Proceedings of ASCILITE 2016 (pp. 648-653). Adelaide. Retrieved from http://2016conference.ascilite.org/wp-content/uploads/ASCILITE-2016-full-proceedings-Updated1512.pdf

Willems, J., Adachi, C., McCluskey, T., Doherty, I., Bussey, F., O’Donnell, M., \& Huijser, H. (2016). The promise and pitfalls of social media use in higher education. In S. Barker, S. Dawson, A. Pardo, \& C. Colvin (Eds.), Show Me the Learning. Proceedings of ASCILITE 2016 (pp. 654-655). Adelaide. Retrieved from http://2016conference.ascilite.org/wp-content/uploads/ASCILITE-2016-full-proceedingsUpdated-1512.pdf

Zheng, B., Niiya, M., \& Warschauer, M. (2015). Wikis and collaborative learning in higher education. Technology, Pedagogy and Education, 24(3), 357-374. https://doi.org/10.1080/1475939X.2014.948041

Corresponding author: Julie Willems, julie.willems@monash.edu

Australasian Journal of Educational Technology @ 2018.

Please cite as: Willems, J., Adachi, C., Bussey, F., Doherty, I., \& Huijser, H. (2018). Debating the use of social media in higher education in Australasia: Where are we now? Australasian Journal of Educational Technology, 34(5), 135-149. https://doi.org/10.14742/ajet.3843 